\title{
Valproic Acid Impairs Carnitine Uptake in Cultured Human Skin Fibroblasts. An In Vitro Model for the Pathogenesis of Valproic Acid- Associated Carnitine Deficiency
}

\author{
I. TEIN, S. Dimauro, Z-W. XIE, AND D. C. DE VIVO \\ The Hospital for Sick Children, Toronto, Ontario, Canada MI5G IX8 [I.T., Z.W'X.], and Columbia University, \\ Now' York, New York, 10032 /S.D.11., D.C.D.I'.]
}

\begin{abstract}
The mechanisms of valproate-associated carnitine deficiency are controversial. The urinary excretion of valproylcarnitine is insufficient to account for tissue carnitine depletion. To explore this mechanism, we studied the effects of valproic acid (VPA) on carnitine uptake in cultured human skin fibroblasts by the method of Tein et al. (Pediatr Res 28:247-255, 1990). Fibroblasts were preincubated with varying concentrations $(0-2000 \mu \mathrm{M})$ of VPA for $1,3,5,7,10,14,21$, and $28 \mathrm{~d}$ and then incubated with fixed carnitine concentrations of $50 \mu \mathrm{M}$ (normal physiologic concentration), $20 \mu \mathrm{M}$ (as seen in secondary carnitine deficiency disorders), or $5 \mu \mathrm{M}$ (as seen in the plasma membrane carnitine transport defect). There was an exponential dose-dependent decrease in carnitine uptake with increasing VPA concentrations, and the relative inhibitory effect was the same for all three carnitine concentrations. The mean percentages \pm SD $(n-1)$ of residual carnitine uptake for all combined preincubation periods (1-28 d) and combined carnitine concentrations $(5,20$, and $50 \mu \mathrm{mol} /$ L) with increasing concentrations of VPA varied from 83.4 $\pm 2.6 \%(10 \mu \mathrm{M}$ VPA $)$ to $56.7 \pm 0.1 \%(500 \mu \mathrm{M})$ to $19.8 \pm$ $1.3 \%(2000 \mu \mathrm{M})$. The degree of inhibition was directly proportional to the time of VPA preincubation and parallel for all three carnitine concentrations; the longer the preincubation period, the lower the toxic dose of VPA (to a minimum of $450 \mu \mathrm{M}$ ), resulting in a $50 \%$ suppression of carnitine uptake $\left(\mathrm{TD}_{50}\right)$. The mean $\mathrm{TD}_{50}$ of the combined carnitine concentrations for increasing preincubation periods of VPA varied from $1898 \pm 214 \mu \mathrm{M}(1 \mathrm{~d})$ to $447 \pm$ $9 \mu \mathrm{M}$ (28 d), tapering toward an asymptote of $450 \mu \mathrm{M}$ when the preincubation period exceeded $14 \mathrm{~d}$. This in vitro $\mathrm{TD}_{50}$ value may be comparable to the in vivo therapeutic range of serum VPA concentrations $(350-700 \mu \mathrm{mol} / \mathrm{L})$ for anticonvulsant therapy. We conclude that one mechanism by which long-term VPA therapy induces serum and tissue carnitine depletion is through inhibition of plasmalemmal carnitine uptake, including decreased renal reabsorption of free carnitine. This effect is directly proportional to the duration of exposure and concentration of VPA. (Pediatr Res 34: 281-287, 1993)
\end{abstract}

Received December 16, 1992; accepted April 2, 1993.

Supported by an Operating Grant from the Medical Research Council of Canada and by a grant from the University of Toronto's Dean's Fund and from the Colleen Giblin Charitable Foundation for Pediatric Neurology Research. I.T. is a recipient of a Medical Research Council of Canada Scholarship.

Correspondence and reprint requests: Dr. Ingrid Tein, Division of Neurology, The Hospital for Sick Children, 555 University Avenue, Toronto, Ontario, M5G IX8 Canada.
Abbreviations

VPA, valproic acid

TD $_{50}$, toxic dose of VPA resulting in $50 \%$ suppression of carnitine uptake

Low serum carnitine concentrations commonly accompany long-term VPA therapy for epilepsy (1-8). Less common but more serious side effects of VPA include a Reye-like syndrome, idiosyncratic and life-threatening hepatotoxicity (distinct from dose-related hepatotoxicity), and pancreatitis (8-16).

Carnitine deficiency in patients with epilepsy may be due to multiple causes, including nutritional deficiency, an underlying inborn error of metabolism, and VPA therapy. Numerous studies have shown a significant decrease in total and/or free serum carnitine concentrations in patients taking multiple anticonvulsants including VPA $(3,17-21)$ or VPA alone (3). However, in one study of 21 children on VPA, the mean serum carnitine concentration did not correlate with either oral VPA dose or serum VPA concentration (22). Even in the presence of normal serum carnitine concentrations, isolated muscle carnitine deficiency was documented in three children receiving chronic VPA therapy for intractable seizures (23). Given that $90 \%$ of body carnitine stores are contained within skeletal muscle (24), this finding suggests that serum carnitine concentrations are not always informative and that muscle carnitine concentrations may provide a more accurate reflection of the carnitine status of the patient. Again, no correlation was found in this study between VPA dose and degree of carnitine depletion, suggesting other mediating factors.

There may be multiple mechanisms of VPA-associated carnitine deficiency including a defect in hepatic biosynthesis, an increase in renal excretion, or a decrease in carnitine transport into tissues. Impairment of carnitine biosynthesis in liver $(25$, 26) would have to be accompanied by a nutritional deficiency to significantly diminish total body carnitine stores because approximately $75 \%$ of carnitine is obtained from the dict (24). Furthermore, carnitine deficiency can occur without significant hepatic dysfunction, implying that other mechanisms are involved.

The renal loss of carnitine as valproylcarnitine has been examined by a number of investigators $(19,22,27)$. Several studies have reported an increased ratio of acylcarnitine to total carnitine in the urine of patients taking VPA, even though the total urinary carnitine excretion was not increased $(19,22)$. Millington $e t$ al. (27) documented decreased free carnitine and increased acylcarnitines in the urine of two children on long-term VPA therapy and reported that valproylcarnitine constituted less than $10 \%$ of the total urinary acylcarnitine pool. Conversely, a marked in- 
crease in urinary carnitine excretion has been documented in one patient with VPA-associated hepatotoxicity (28). However, it is still unproven whether long-term VPA therapy with continued urinary excretion of valproylcarnitine depletes total body stores of carnitine leading to a deficiency state.

A defect in tissue carnitine transport could explain both serum depletion caused by decreased renal tubular reabsorption of free carnitine and muscle depletion caused by decreased muscle uptake. Evidence is emerging that muscle, kidney, and fibroblasts share a common plasmalemmal carnitine transporter $(29,30)$. Fibroblasts have become a useful model to examine the "musclekidney" carnitine transport system $(30,31)$. Therefore, we studied the effect of increasing VPA concentrations and increasing time periods of VPA preincubation on carnitine uptake in cultured human skin fibroblasts. To determine the relative severity of the VPA effect in different clinical conditions, we also varied the carnitine concentrations in the incubation medium to simulate serum carnitine concentrations seen in normal controls and in primary and secondary carnitine deficiency disorders.

\section{MATERIALS AND METHODS}

All studies were performed with the approval of the Institutional Review Board of The Hospital for Sick Children, Toronto. Carnitine uptake studies were performed in control cultured skin fibroblasts with documented normal carnitine uptake. Control fibroblasts were obtained from the Human Genetic Mutant Cell Repository, Coriell Institute for Medical Research, Camden, NJ. The uptake of carnitine was investigated by the method of Tein et al. (30). Control fibroblasts (passage numbers 6-12) were plated onto 9.5-cm six-well plates (Gibco Laboratories, St. Lawrence, MA) and allowed to grow to confluence in RPMI 1640 medium supplemented with $10 \%$ FCS (medium total carnitine, $2 \mu \mathrm{mol} / \mathrm{L})$. L-[methyl $\left.{ }^{3} \mathrm{H}\right]$ carnitine hydrochloride was purchased from Amersham, Arlington Heights, IL, and L-carnitine was a gift from Sigma-Tau Pharmaceuticals, Pomezia, Italy. Cellbound radioactivity was determined in $800 \mu \mathrm{L}$ of the final fibroblast hydrolysate using Aquasol- 2 with a counting efficiency of $60 \%$. Cell protein was measured in the remaining $200 \mu \mathrm{L}$ of the hydrolysate for each individual plate by the method of Lowry et al. (32). VPA (2-propylpentanoic acid) was used as supplied from Sigma Chemical Co., St. Louis, MO. Experiments with VPA were run in parallel with a standard control carnitine uptake study without VPA. Nonspecific uptake was determined at 10 $\mathrm{mmol} / \mathrm{L}$ carnitine. VPA concentrations in the preincubation medium of RPMI 1640 and $10 \%$ FCS were fixed at $0,100,200$, $300,500,700,900,1100,1300,1500,1700$, and $2000 \mu \mathrm{mol} / \mathrm{L}$. At the beginning of the uptake study, the plates were thoroughly washed four times with PBS to remove all excess FCS. The individual wells were then incubated with the same predetermined concentrations of VPA, in RPMI without FCS, and a fixed carnitine concentration of 5,20 , or $50 \mu \mathrm{mol} / \mathrm{L}$, for the measurement of $\left[{ }^{3} \mathrm{H}\right]$-L-carnitine uptake in vitro. The VPA preincubation periods were varied from $4 \mathrm{~h}$ (actual incubation period of uptake study) to $1,3,5,7,10,14,21$, and $28 \mathrm{~d}$. Reproducibility of results was confirmed by repeat experiments using the identical VPA concentration, time period of VPA preincubation, and carnitine substrate incubation concentration, on three separate days. Specific uptake of radioactivity was used to calculate the rates of total carnitine uptake. Apparent $\mathrm{Km}$ and $\mathrm{V}_{\max }$ values for standard carnitine uptake studies were obtained by linear regression analysis of Lineweaver-Burk plots.

Carnitine uptake was examined against increasing VPA preincubation concentrations for each of the three carnitine incubation concentrations $(5,20,50 \mu \mathrm{M})$ under eight fixed VPA preincubation periods ( $1-28 \mathrm{~d}$ ) for triplicate experiments ( 72 analyses). The curves of residual carnitine uptake with increasing concentrations of VPA were plotted together for the different VPA preincubation periods. The mean of the residual carnitine uptake from all VPA incubation periods was determined for each of the three carnitine concentrations and plotted against increasing concentrations of VPA to demonstrate the net effect of increasing VPA concentrations. The TD $\mathrm{TD}_{50}$ of VPA resulting in a $50 \%$ suppression of carnitine uptake was determined by nonlinear regression analysis of dose-response curves plotting carnitine uptake versus increasing VPA concentrations. The statistical nonlinear regression analysis program (Systat 5.0) was obtained from Systat Inc., Evanston, IL. These dose-response curves were individually analyzed for each of the three carnitine incubation concentrations $(5,20,50 \mu \mathrm{M})$ under eight fixed VPA preincubation periods (1-28 d) for triplicate experiments (72 analyses). The mean $\mathrm{TD}_{s 0}$ (triplicate experiments) for the individual carnitine concentrations were then plotted against increasing time of VPA preincubation to establish the time period of maximum effect.

\section{RESULTS}

During the 4-h incubation period of the uptake study without any preincubation, VPA had no significant effect on carnitine uptake at the lower concentrations and only a minor effect at the highest concentration of $2000 \mu \mathrm{mol} / \mathrm{L}$ (15\% reduction in carnitine uptake). Significant effects were initially demonstrated with a preincubation period of $24 \mathrm{~h}$ (Fig. 1a). The curves of residual carnitine uptake with increasing concentrations of VPA ( 0 to $2000 \mu \mathrm{mol} / \mathrm{L}$ ) were plotted for each of the three carnitine incubation concentrations $(5,20,50 \mu \mathrm{mol} / \mathrm{L})$ under each of the eight VPA preincubation periods (1-28 d) using nonlinear regression analysis.

To examine the rate of decline with increasing VPA preincubation periods, the individual curves from four preincubation periods for a fixed carnitine incubation concentration (e.g. 50 $\mu \mathrm{mol} / \mathrm{L}$ ) were collated on the same graph as shown in Figure $1 a$ (VPA preincubation periods of $1,3,5$, and $7 \mathrm{~d}$ ) and Figure $1 b$ (VPA preincubation periods of $10,14,21$, and $28 \mathrm{~d}$ ). To examine the isolated net effect of increasing VPA concentrations on carnitine uptake, the mean of the residual carnitine uptake from all VPA preincubation periods was subsequently determined for
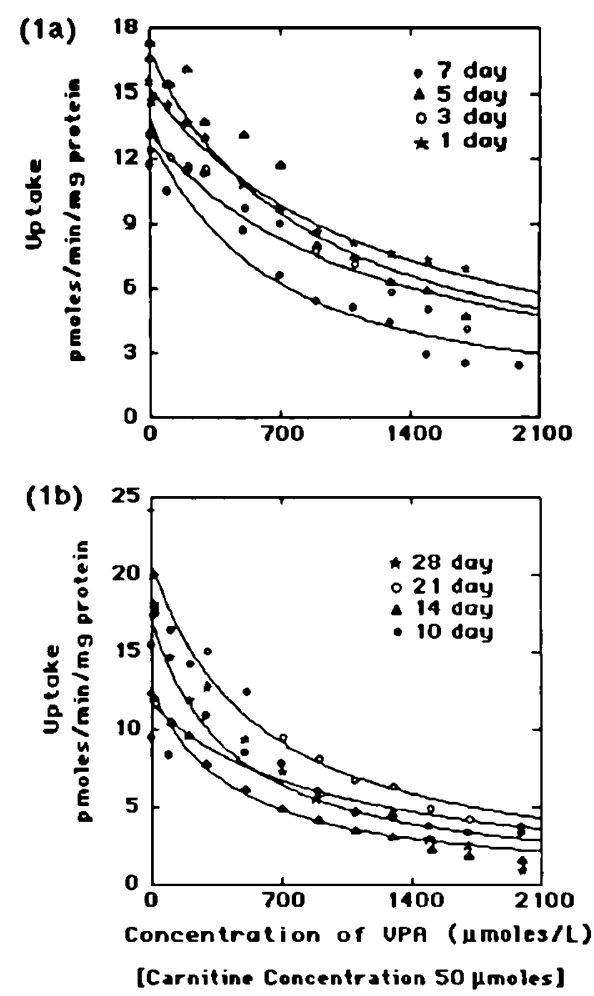

Fig. 1. Effect of increasing VPA concentration on carnitine uptake with carnitine substrate concentration of $50 \mu \mathrm{mol} / \mathrm{L}$. 
each of the three carnitine concentrations and plotted against increasing VPA concentrations (Fig. 2). The mean values are listed in Table 1 with the calculated percentages of residual uptake. There was no significant difference in the relative rates of decline of carnitine uptake with increasing VPA concentrations at the different carnitine concentrations. Although the percentage decrease of carnitine uptake was not affected by the initial carnitine concentration, the absolute values of carnitine uptake were lowest at $5 \mu \mathrm{mol} / \mathrm{L}$ carnitine concentration, intermediate at $20 \mu \mathrm{mol} / \mathrm{L}$, and highest at $50 \mu \mathrm{mol} / \mathrm{L}$ concentration. The mean percentages [ $\pm \mathrm{SD}(n-1)]$ of residual carnitine uptake for the combined VPA preincubation periods and the combined carnitine concentrations $(5,20,50 \mu \mathrm{mol} / \mathrm{L})$ plotted against increasing concentrations of VPA demonstrated a

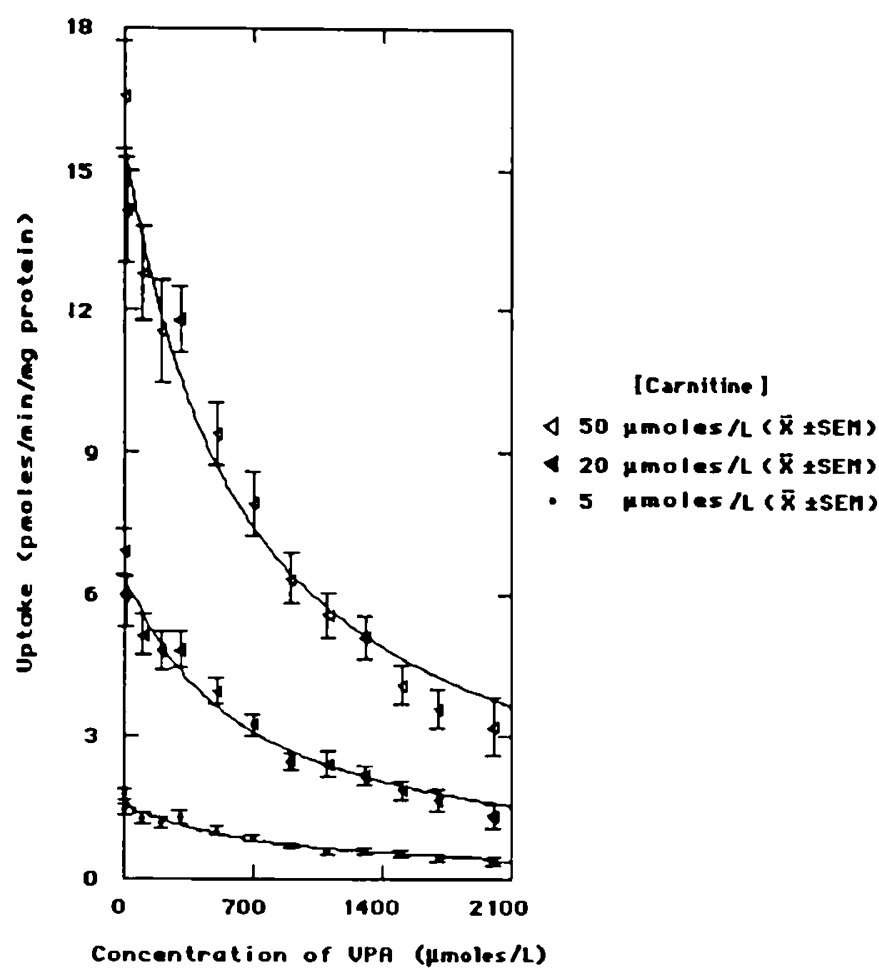

Fig. 2. Effect of increasing VPA concentrations on mean carnitine uptake from all combined VPA preincubation periods (1-28 d). marked inverse dose-response effect with increasing VPA concentration (Table 1).

The dose-response curves of carnitine uptake versus increasing VPA concentration were individually analyzed for each of the three carnitine incubation concentrations $(5,20,50 \mu \mathrm{mol} / \mathrm{L})$ under the eight fixed VPA preincubation periods (1-28 d) for triplicate experiments (Fig. 3). The $\mathrm{TD}_{s 0}$ of VPA resulting in a $50 \%$ suppression of carnitine uptake was determined by nonlinear regression analysis of the dose-response curves for the individual carnitine concentrations and the means determined. The degree of inhibition of carnitine uptake was directly proportional to the time of VPA incubation, and parallel for all three carnitine concentrations (Fig. 4, Table 2); the longer the preincubation period, the lower the $T_{50}$ of VPA that tapered toward an asymptote of $450 \mu \mathrm{M}$ when the preincubation period was $\geq 14$ $\mathrm{d}$. The maximum effect of VPA preincubation time on carnitine uptake, regardless of the carnitine incubation concentration, was reached by 10-14 d of VPA exposure, beyond which there was no significant additional effect on the $\mathrm{TD}_{50}$. Of note, the mean in vitro $\mathrm{TD}_{50}$ values for VPA preincubations of 7-28 d, namely $560-450 \mu \mathrm{mol} / \mathrm{L}$, may be comparable to the in vivo therapeutic range of serum VPA concentrations $(350-700 \mu \mathrm{mol} / \mathrm{L})$, which is used as a general guideline for VPA anticonvulsant therapy in epileptic patients. Preincubation periods of $1-28 \mathrm{~d}$ in standard control uptake plates without VPA (run in parallel with the VPA experiment plates) showed no significant decrease of carnitine uptake.

\section{DISCUSSION}

Carnitine concentrations in most tissues, except brain, are 20 to 50 -fold higher than in serum (33). Carnitine uptake is mediated by a transport system, apparently driven by a large sodium potential across the plasma membrane $(34,35)$ and generally held to be energy-dependent (36-38). In studies of children with primary systemic carnitine deficiency, a genetically determined defect in plasmalemmal carnitine transport has been documented in cultured skin fibroblasts $(29,30)$. Clinically, these children present with hypotonia, weakness, lethargy, cardiomyopathy, fasting hypoglycemia, hypoketotic encephalopathy, and failure to thrive. Because these patients have a markedly decreased renal threshold for carnitine and are incapable of fully restoring muscle carnitine concentrations despite high-dose oral carnitine supplementation and almost complete restoration of normal serum carnitine concentrations, it has been postulated

Table 1. Effect of increasing VPA concentrations on mean carnitine uptake*

\begin{tabular}{|c|c|c|c|c|c|c|c|}
\hline & \multicolumn{6}{|c|}{ Carnitine incubation concentration } & \multirow{3}{*}{$\begin{array}{l}\text { Combined mean of } \\
5,20, \text { and } 50 \mu \mathrm{M} \\
\text { [\% Residual uptake } \\
\pm \mathrm{SD}(n-1)]\end{array}$} \\
\hline & \multicolumn{2}{|c|}{$5 \mu \mathrm{M}$ Carnitine } & \multicolumn{2}{|c|}{$20 \mu \mathrm{M}$ Carnitine } & \multicolumn{2}{|c|}{$50 \mu \mathrm{M}$ Carnitine } & \\
\hline & Uptake† & $\begin{array}{c}\text { \% Residual } \\
\text { uptake }\end{array}$ & Uptake & $\begin{array}{c}\% \text { Residual } \\
\text { uptake }\end{array}$ & Uptake & $\begin{array}{c}\% \text { Residual } \\
\text { uptake }\end{array}$ & \\
\hline \multicolumn{8}{|c|}{$\mathrm{VPA} \mu \mathrm{M}$} \\
\hline 0 & 1.750 & 100.0 & 6.930 & 100.0 & 16.592 & 100.0 & 100.0 \\
\hline 10 & 1.408 & 80.5 & 5.854 & 84.5 & 14.155 & 85.3 & $83.4 \pm 2.57$ \\
\hline 100 & 1.239 & 70.8 & 5.144 & 74.2 & 12.747 & 77.1 & $74.0 \pm 3.15$ \\
\hline 200 & 1.144 & 65.4 & 4.792 & 69.1 & 11.565 & 69.7 & $68.1 \pm 2.33$ \\
\hline 300 & 1.285 & 73.4 & 4.824 & 69.6 & 11.804 & 71.1 & $71.4 \pm 1.91$ \\
\hline 500 & 0.993 & 56.7 & 3.933 & 56.7 & 9.420 & 56.8 & $56.7 \pm 0.06$ \\
\hline 700 & 0.852 & 48.7 & 3.220 & 46.5 & 7.944 & 47.9 & $47.7 \pm 1.11$ \\
\hline 900 & 0.673 & 38.4 & 2.453 & 35.4 & 6.344 & 38.2 & $37.3 \pm 1.68$ \\
\hline 1100 & 0.576 & 32.9 & 2.388 & 34.4 & 5.563 & 33.5 & $33.6 \pm 0.87$ \\
\hline 1300 & 0.564 & 32.2 & 2.138 & 30.8 & 5.086 & 30.6 & $31.2 \pm 0.87$ \\
\hline 1500 & 0.507 & 29.0 & 1.852 & 26.7 & 4.074 & 24.6 & $26.8 \pm 2.20$ \\
\hline 1700 & 0.442 & 25.3 & 1.628 & 23.5 & 3.565 & 21.5 & $23.4 \pm 1.90$ \\
\hline 2000 & 0.372 & 21.3 & 1.303 & 18.8 & 3.182 & 19.2 & $19.8 \pm 1.34$ \\
\hline
\end{tabular}

* Combined means for eight incubation periods (1-28 d) and triplicate experiments $(n=24)$.

† Uptake expressed in $\mathrm{pmol} / \mathrm{min} / \mathrm{mg}$ fibroblast protein. 
(se) VPA-1 Day Pre-1 ncubation Portod
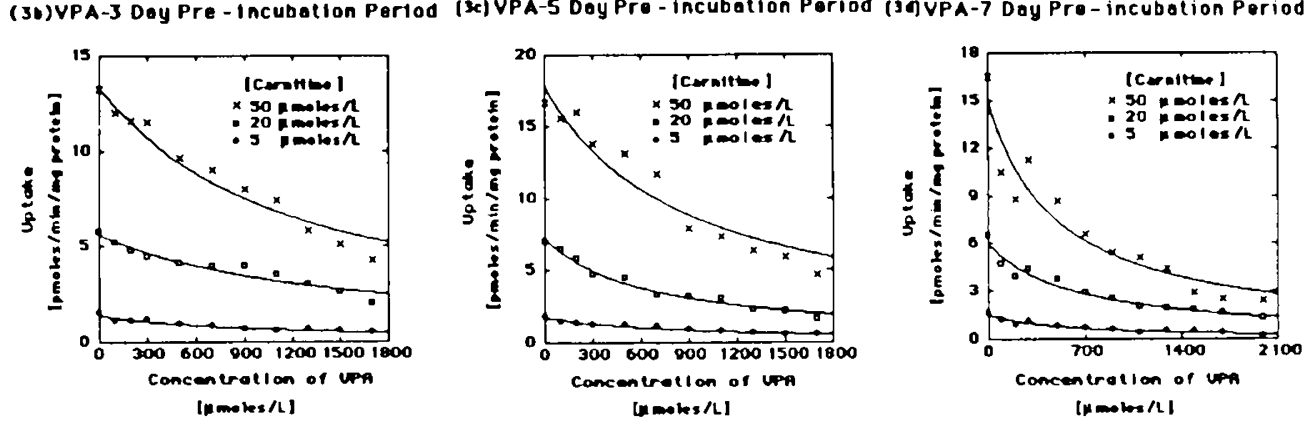

(3o)VPA-10 Doy Pre-incubation Period
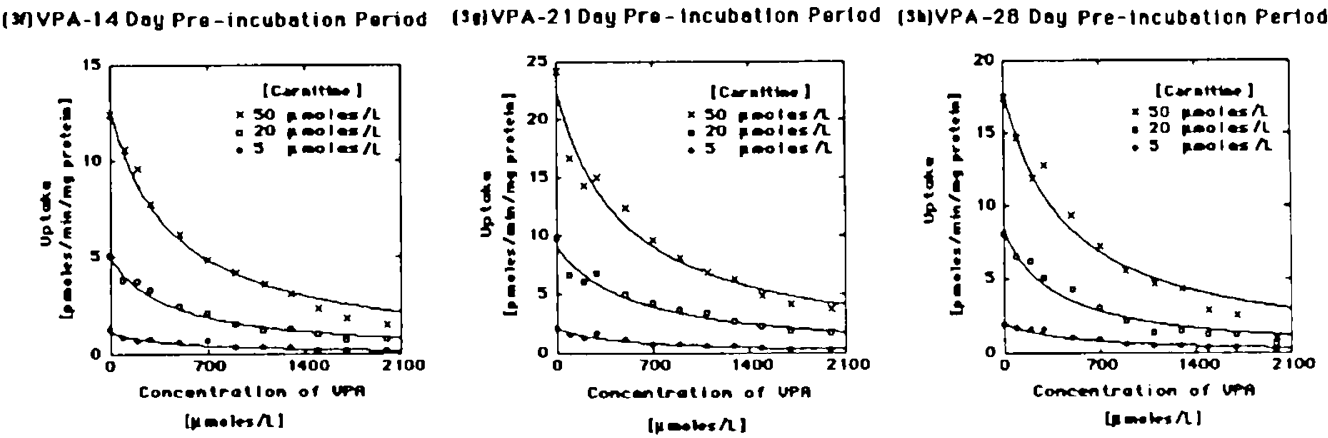

Fig. 3. Effect of increasing VPA preincubation periods on carnitine uptake.

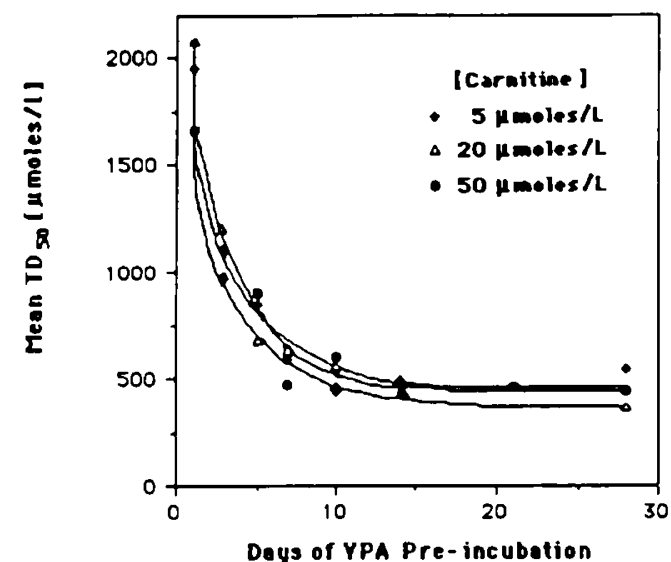

Fig. 4. Effect of increasing VPA preincubation periods on mean toxic dose of VPA causing $50 \%$ decrease $\left(\mathrm{TD}_{50}\right.$ ) of carnitine uptake.

that muscle, kidney, and fibroblasts share a common plasmalemmal carnitine transporter $(29,30)$. This concept is supported by the similar $\mathrm{Km}$ values for carnitine uptake in cultured muscle $(1.90 \pm 1.38 \mu \mathrm{M})(39)$, human heart cells $(4.8 \pm 2.2 \mu \mathrm{M})(40)$, and skin fibroblasts $(5.5 \pm 0.58 \mu \mathrm{M})(30)$, which are very different from the $\mathrm{Km}$ values observed in human liver $(500 \mu \mathrm{M})$ and brain $(>1000 \mu \mathrm{M})(41)$. A VPA-associated defect in carnitine transport could mimic the genetically determined defect in plasmalemmal carnitine transport and could result in decreased renal tubular reabsorption of free carnitine and explain the isolated deficiency of muscle carnitine documented in three patients on long-term VPA therapy (23).

We therefore investigated the effect of increasing concentrations and exposure periods of VPA on plasmalemmal carnitine uptake in cultured control human skin fibroblasts at three carnitine concentrations. There was an exponential dose-dependent decrease in carnitine uptake with increasing VPA concentration. The relative inhibitory effect of increasing VPA concentrations on carnitine uptake was the same for all three carnitine concentrations. The degree of inhibition was directly proportional to the time of VPA exposure and parallel for all three carnitine concentrations. The mean $\mathrm{TD}_{50}$ tapered toward a minimum asymptote of $450 \mu \mathrm{mol} / \mathrm{L}$ of VPA when the preincubation period was $\geq 14 \mathrm{~d}$ and did not decrease further thereafter. This in vitro VPA concentration may be comparable to the in vivo therapeutic range of serum VPA concentrations (350-700 $\mu \mathrm{mol} / \mathrm{L}$ ) for anticonvulsant therapy. At $1 \mathrm{~d}$ of incubation, the $\mathrm{TD}_{50}$ was well above "therapeutic range" (TD so $_{50}$ of $1898 \mu \mathrm{mol} / \mathrm{L}$ ) but decreased dramatically by $3 \mathrm{~d}\left(\mathrm{TD}_{50}\right.$ of $\left.1096 \mu \mathrm{mol} / \mathrm{L}\right)$ approaching high therapeutic levels. No significant effect on carnitine uptake was noted after $4 \mathrm{~h}$ of incubation with VPA, with the exception of a minor decrease $(15 \%)$ in uptake at the highest concentration of $2000 \mu \mathrm{mol} / \mathrm{L}$, which is three times the normal therapeutic range. Thus, significant VPA inhibition of carnitine uptake appears to require a period of several days and reaches maximum effect by approximately $10-14 \mathrm{~d}$. This could be compatible with the observation that $75 \%$ of cases of idiosyncratic fatal hepatotoxicity occur within the first 3 mo of therapy (42).

There are at least four different mechanisms by which VPA can interfere with carnitine uptake. One mechanism could be the direct inhibition of carnitine uptake by valproylcarnitine. VPA (2-propylpentanoic acid), an eight-carbon fatty acid, is assumed to pass freely through the mitochondrial membrane in a carnitine-independent manner (43). VPA is then probably converted into its activated intermediate, valproyl-CoA (2-propyl-pentanoyl-CoA), as demonstrated in rat liver mitochondria (43). As proposed by Millington et al. (27), valproyl-CoA is probably converted into valproylcarnitine by one or more of the carnitine acyltransferases, predominantly carnitine octanoyltransferase, at the inner surface of the inner mitochondrial membrane. We suggest that valproylcarnitine may then be transported out of the mitochondrion, leaving behind free $\mathrm{CoA}$ within the mitochondria. The valproylcarnitine may diffuse across the plasmalemma and then interfere with tissue free carnitine transport or renal tubular reabsorption of free carnitine. Depressed renal tubular reabsorption of free carnitine has been documented by Matsuda and Ohtani (28) in children receiving VPA therapy. Stanley et al. (44) examined the renal free carnitine threshold (plasma level at which urinary free carnitine fell below $5 \%$ of the filtered load) and also found that it was below the normal range 
Table 2. Effect of increasing VPA preincubation time on mean $T D_{50}$ of VPA for carnitine uptake*

\begin{tabular}{|c|c|c|c|c|c|c|c|c|}
\hline & \multicolumn{8}{|c|}{ VPA preincubation time (d) } \\
\hline & 1 & 3 & 5 & 7 & 10 & 14 & 21 & 28 \\
\hline \multicolumn{9}{|l|}{ Carnitine incubation concentration } \\
\hline $5 \mu \mathrm{M}$ & 1954 & 978 & 849 & 589 & 454 & 492 & 450 & 535 \\
\hline $20 \mu \mathrm{M}$ & 2079 & 1209 & 674 & 624 & 569 & 449 & 459 & 366 \\
\hline $50 \mu \mathrm{M}$ & 1662 & 1100 & 895 & 467 & 590 & 430 & 457 & 433 \\
\hline $\begin{array}{l}\text { Combined mean of } 5,20 \text {, and } 50 \mu \mathrm{M} \\
\quad \pm \operatorname{SD}(n-1)\end{array}$ & $1898 \pm 214$ & $1096 \pm 115$ & $806 \pm 116$ & $560 \pm 82$ & $538 \pm 73$ & $437 \pm 32$ & $456 \pm 5$ & $447 \pm 9$ \\
\hline
\end{tabular}

of plasma free carnitine $(36-50 \mu \mathrm{mol} / \mathrm{L})$ in medium-chain acylCoA dehydrogenase deficiency $(17 \mu \mathrm{mol} / \mathrm{L})$ and in long-chain acyl-CoA dehydrogenase deficiency $(40 \mu \mathrm{mol} / \mathrm{L})$ compared with controls $(57 \mu \mathrm{mol} / \mathrm{L})$. In a subsequent report, Stanley et al. (31) found that the "muscle-kidney carnitine transport system" expressed in cultured skin fibroblasts was strongly inhibited by acylcarnitines $(50 \%$ inhibition at $3.05 \mu \mathrm{mol} / \mathrm{L}$ L-carnitine, 4.6 $\mu \mathrm{mol} / \mathrm{L}$ acetylcarnitine, $2.9 \mu \mathrm{mol} / \mathrm{L}$ octanoylcarnitine, and 0.37 $\mu \mathrm{mol} / \mathrm{L}$ palmitoylcarnitine). It was therefore suggested that the secondary carnitine deficiency seen in intramitochondrial $\beta$ oxidation defects may reflect inhibition of free carnitine transport by medium- or long-chain acylcarnitines rather than excessive excretion of the acylcarnitines themselves (31). This concept is also supported by the work of Nishida $e t$ al. (45) in VPA-treated rats.

An indirect mechanism by which VPA could interfere with carnitine uptake into tissues would be through the formation of VPA metabolites, e.g. 4-en valproate (46), with secondary inhibition of $\beta$-oxidation and accumulation of excessive acyl-CoA derivatives. VPA is almost entirely cleared through $\beta$-oxidation and glucuronidation (12). In mitochondria, VPA is converted to 2-propylpentanoyl-CoA, which is dehydrogenated to 2-propyl-2pentanoyl-CoA by 2-methyl-branched-chain acyl-CoA dehydrogenase (47) and subsequently hydrated by enoyl-CoA hydratase to 3-hydroxy-2-propylpentanoyl-CoA (43). Li et al. (43) have demonstrated that the latter compound is dehydrogenated by a novel $\mathrm{NAD}^{+}$-specific 3-hydroxyacyl-CoA dehydrogenase associated with the mitochondrial membrane to 3-keto-2-propylpentanoyl-CoA, which is then slowly degraded most likely by hydrolysis. Kesterson et al. (46) studied the hepatotoxic effects of VPA and its metabolites in rats and found that 4-PA, 4-en-VPA, and 2,4-dien-VPA were potent inducers of microvesicular steatosis in young rats. 4-en-VPA produced ultrastructural changes characterized by myeloid bodies, lipid vacuoles, and mitochondrial abnormalities. In other studies, VPA was shown to be toxic to rat liver mitochondria both in vitro (48) and in vivo (49). The morphologic swelling of rat liver mitochondria exposed to VPA could be prevented by simultaneously giving L-carnitine (49). In mice injected with VPA, hepatic concentrations of CoA and free carnitine decreased, whereas acylcarnitine concentrations increased (50). In isolated rat hepatocytes, VPA inhibited oxidation of $\left[1-{ }^{14} \mathrm{C}\right]$ palmitate and decreased ketogenesis and acetyl-CoA levels (51).

In terms of mechanisms, it has been suggested that VPA may inhibit $\beta$-oxidation in humans and rats either by sequestering CoA or by increasing the acyl-CoA:free CoA ratio $(46,52,53)$. Secondly, Li et al. (43) have suggested that trapping of a finite pool of $\mathrm{CoA}$ also may deplete the reduced $\mathrm{CoA}$ needed for the thiolytic cleavage of 3-ketoacyl-CoA thereby inhibiting $\beta$-oxidation. A third possible mechanism of inhibition suggested by $\mathrm{Li}$ et al. (43) would be the inhibition of one or more $\beta$-oxidation enzymes by 3-keto-2-propylpentanoyl-CoA. This compound, serving as substrate or product analogue, could bind to 3-ketoacyl-CoA thiolase and 3-hydroxyacyl-CoA dehydrogenase, without being acted on by these enzymes, thereby functioning as an inhibitor (43). A related metabolite, 4-pentenoic acid, when metabolized by $\beta$-oxidation to 3-keto-4-pentenoyl-CoA, has been shown to be a potent inhibitor of 3-ketoacyl-CoA thiolase and of acetoacetyl-CoA thiolase (54). VPA and its metabolites could therefore inhibit enzymes of $\beta$-oxidation and have potent and long-term effects. Carnitine could be used for the formation of acylcarnitines to buffer these potentially toxic acyl-CoA derivatives that accumulate proximal to the block in fatty acid $\beta$ oxidation. The increasing inhibitory effect on carnitine uptake that we observed with increasing preincubation periods of VPA may therefore relate to the accumulation, over time, of acylcarnitines including valproylcarnitine that may then diffuse into the incubation medium and interfere with free carnitine uptake into the cell. The lack of further inhibition after $14 \mathrm{~d}$ of VPA preincubation may relate to severe inhibition of intramitochondrial $\beta$-oxidation with no further increase in acylcarnitine formation or to saturation of the inhibitory effect of acylcarnitines at the carnitine plasmalemmal transport site.

Finally, a decrease in intracellular ATP due to inhibition of $\beta$ oxidation, pyruvate metabolism, and gluconeogenesis could account for decreased efficiency of the energy-dependent carnitine transporter. Sequestration of free $\mathrm{CoA}$ through formation of valproyl-CoA $(52,53)$ would decrease ATP production. VPA also interferes with pyruvate uptake by rat brain mitochondria (55) and inhibits pyruvate oxidation as well as the activities of pyruvate carboxylase and pyruvate dehydrogenase (53). In addition, VPA may lead to uncoupling of mitochondrial oxidation (55) and inhibition of oxidative phosphorylation $(48,56,57)$, possibly in part through inhibition of cytochrome $a a_{3}$ activity (58). Furthermore, VPA inhibits gluconeogenesis in rat liver (52, $53,59)$ possibly through inhibition of pyruvate carboxylase $(53)$. These several observations, in the aggregate, suggest that VPA may compromise cellular energetics by a variety of mechanisms.

Clinically, there has been much interest in the role of the carnitine deficiency in predisposing a child on VPA therapy to the idiosyncratic, potentially life-threatening Reye-like syndrome (13). Several patients with a Reye-like syndrome caused by VPA were shown to have carnitine deficiency $(8,17,28)$ but others did not (3). Some patients may have a preexisting carnitine deficiency due to an inborn error of metabolism (60); however, this is not true for all $(3,17)$. The patients at greatest risk for VPA hepatotoxicity ( 1 of 500) are children under the age of $2 y$ with neurologic disabilities who are receiving multiple anticonvulsants (42). The clinical scenario for fatal hepatotoxicity may be as follows. Seizures may be the clinical signature of a genetically determined metabolic error such as "Alpers syndrome" (progressive infantile poliodystrophy with cirrhosis) or an intramitochondrial $\beta$-oxidation disorder, which also may be associated with secondary carnitine deficiency. This metabolic condition may be further exacerbated by VPA. Young children may be more prone to decreased carnitine stores because of decreased carnitine biosynthesis and decreased intake. Other anticonvulsants may increase potentially hepatotoxic VPA metabolites, having a synergistic effect. When VPA leads to carnitine deficiency, this interferes with long-chain fatty acid oxidation. VPA also may reduce the available free $\mathrm{CoA}$ for $\beta$-oxidation, which could lead to the accumulation of potentially toxic short-chain fatty acids (7). In every case, a thorough investigation should be conducted to determine whether the epileptic patient has an 
associated inborn metabolic error predisposing him or her to this idiosyncratic complication $(24,61)$.

In summary, the carnitine deficiency associated with VPA therapy may be due to several different mechanisms. One mechanism is through inhibition of plasmalemmal carnitine uptake into tissues, which could include decreased renal tubular reabsorption of free carnitine. Our studies show that this effect is directly proportional to the duration of exposure and concentration of VPA. We propose that the inhibition may be due to increasing competition between free carnitine and acylcarnitines, including valproylcarnitines and short-chain acylcarnitines, at the plasmalemmal transporter site. We suggest that L-carnitine supplementation may decrease the apparent impairment of plasmalemmal free carnitine uptake into tissues and of free carnitine reabsorption in the kidneys through an increase in the free carnitine concentration at the transport site. Additional studies are necessary to support this hypothesis. As well, increased free carnitine would provide a greater buffering capacity for excessive potentially toxic acyl-CoA including valproyl-CoA, thereby decreasing secondary inhibition of fatty acid oxidation, pyruvate oxidation, and gluconeogenesis and increasing the intramitochondrial free CoA concentration. Because there is no evidence that L-carnitine administration adversely alters the anticonvulsant properties of VPA (62) or lowers the serum VPA concentration, our data suggest that carnitine should be administered to all children on VPA who have laboratory or clinical evidence of serum or tissue carnitine deficiency.

\section{REFERENCES}

1. Winter SC, Szabo-Aczel S, Curry CJ, Hutchinson HT, Hogue R, Shug A 1987 Plasma carnitine deficiency. Clinical observations in 51 pediatric patients. Am J Dis Child 141:660-665

2. Stumpf DA, Parker Jr WD, Angelini C 1985 Carnitine deficiency, organic acidemias, and Reye's syndrome. Neurology 35:1041-1045

3. Laub MC, Paezke-Brunner I, Jaeger G 1986 Serum carnitine during valproic acid therapy. Epilepsia 27:559-562

4. Ohtani $Y$, Endo F, Matsuda I 1982 Carnitine deficiency and hyperammonemia associated with valproic acid therapy. J Pediatr 101:782-785

5. Matsuda I, Ohtani Y, Ninomiya N 1986 Renal handling of carnitine in children with carnitine deficiency and hyperammonemia associated with valproate therapy. J Pediatr 109:131-134

6. Coulter DL 1984 Carnitine deficiency: a possible mechanism for valproate hepatotoxicity. (letter) Lancet 1:689

7. Coulter DL 1991 Carnitine, valproate, and toxicity. J Child Neurol 6:7-14

8. Böhles H, Richter K. Wagner-Thiessen E, Schäfer H 1982 Decreased serum carnitine in valproate induced Reye syndrome. Eur J Pediatr 139:185-186

9. Addison GM. Gordon NS 1980 Sodium valproate and acute hepatic failure. Dev Med Child Neurol 22:248-249

10. Coulter DL, Allen RJ 1980 Pancreatitis associated with valproic acid therapy for epilepsy (letter) Ann Neurol 7:92

11. Dreifuss FE, Langer DH, Moline KA, Maxwell JE 1989 Valproic acid hepatic fatalities. IL US experience since 1984. Neurology 39:201-207

12. Eadie MJ, Hooper WD, Dickinson RG 1988 Valproate-associated hepatotoxicity and its biochemical mechanisms. Med Toxicol Adverse Drug Exp 3:85-106

13. Gerber N, Dickinson RG, Harland RC, Lynn RK, Houghton D, Antonias JI. Schimschock JC 1979 Reye-like syndrome associated with valproic acid therapy. J Pediatr 95:142-144

14. Suchy FJ, Balistreri WF, Buchino JJ, Sondheimer JM, Bates SR, Kearns GL, Stull JD, Bove KE 1979 Acute hepatic failure associated with the use of sodium valproate. N Engl J Med 300:962-966

15. Wyllie E, Wyllie R, Cruse RP, Erenberg G, Rothner AD 1984 Pancreatitis associated with valproic acid therapy. Am J Dis Child 138:912-914

16. Zimmerman HJ, Ishak KG 1982 Valproate-induced hepatic injury: analyses of 23 fatal cases. Hepatology 2:591-597

17. Murphy JV, Marquardt KM, Shug AL 1985 Valproic acid associated abnormalities of carnitine metabolism. (letter) Lancet 1:820-821

18. Morita J, Yuge K, Yoshino M 1986 Hypocarnitinemia in the handicapped individuals who receive a polypharmacy of antiepileptic drugs. Neuropediatrics 17:203-205

19. Melegh B, Kerner J, Kispál G, Acsádi G, Acsádi G, Dani M 1987 Effect of chronic valproic acid treatment on plasma and urine carnitine levels in children: decreased urinary excretion. Acta Paediatr Hung 28:137-142

20. Rodriguez-Segade S, de la Peña CA. Tutor JC, Paz JM, Fernandez MP, Rozas I, Del Rio R 1989 Carnitine deficiency associated with anticonvulsant therapy. Clin Chim Acta 181:175-181

21. Beghi E, Bizzi A, Codegoni AM, Trevisan D. Torri W 1990 Valproate, carnitine metabolism, and biochemical indicators of liver function. Collaborative Group for the Study of Epilepsy. Epilepsia 31:346-352
22. Murphy JV, Marquardt KM. Shug A 1984 Plasma and urine carnitine concentrations in patients receiving valproic acid. Pediatr Res 18:380A(abstr)

23. Shapira Y, Gutman A 1991 Muscle carnitine deficiency in patients using valproic acid. J Pediatr 118:646-649

24. De Vivo DC, Tein I 1990 Primary and secondary disorders of carnitine metabolism. Int Pediatr 5:134-141

25. Rebouche CJ, Engel AG 1980 In vitro analysis of hepatic carnitine biosynthesis in human systemic carnitine deficiency. Clin Chim Acta 106:295-300

26. Englard S 1979 Hydroxylation of gamma-butyrobetaine to carnitine in human and monkey tissues. FEBS Lett 102:297-300

27. Millington DS, Bohan TP, Roe CR, Yergey AL, Liberato DJ 1985 Valproylcarnitine: a novel drug metabolite identified by fast atom bombardment and thermospray liquid chromatography-mass spectrometry. Clin Chim Acta 145:69-76

28. Matsuda I, Ohtani Y 1986 Carnitine status in Reye and Reye-like syndromes. Pediatr Neurol 2:90-94

29. Treem WR, Stanley CA, Finegold DN, Hale DE, Coates PM 1988 Primary carnitine deficiency due to a failure of carnitine transport in kidney, muscle, and fibroblasts. N Engl J Med 319:1331-1336

30. Tein I, De Vivo DC, Bierman F, Pulver P, De Meirleir LJ, Cvitanovic-Sojat L, Pagon RA, Bertini E, Dionisi-Vici C, Servidei S, DiMauro S 1990 Impaired skin fibroblast carnitine uptake in primary systemic carnitine deficiency manifested by childhood carnitine-responsive cardiomyopathy. Pediatr Res 28:247-255

31. Stanley CA, Deleeuw S, Coates PM, Vianey-Liaud C, Divry P, Bonnefont JP, Saudubray J-M, Haymond M, Trefz FK, Breningstall GN, Wappner RS Byrd DJ, Sansarica C, Tein I, Grover W, Valle D, Rutledge SL, Treem WR 1991 Chronic cardiomyopathy and weakness or acute coma in children with a defect in carnitine uptake. Ann Neurol 30:709-716

32. Lowry OH, Rosebrough NJ, Farr AL, Randall RJ 1951 Protein measurement with the Folin phenol reagent. J Biol Chem 193:265-275

33. Stanley CA 1987 New genetic defects in mitochondrial fatty acid oxidation and carnitine deficiency. Adv Pediatr 34:59-88

34. Bremer J 1983 Carnitine: metabolism and functions. Physiol Rev 63:14201480

35. Rebouche CJ, Mack DL 1984 Sodium gradient-stimulated transport of Lcarnitine into renal brush border membrane vesicles: kinetics, specificity, and regulation by dietary carnitine. Arch Biochem Biophys 235:393-402

36. Huth PJ, Thomsen JH, Shug AL 1978 Carnitine transport by rat kidney cortex slices: stimulation by dibutyryl cyclic AMP+. Life Sci 23:715-722

37. Huth PJ. Shug A 1980 Properties of carnitine transport in rat kidney cortex slices. Biochim Biophys Acta 602:621-634

38. Kispal G, Melegh B, Alkonyi I. Sandor A 1987 Enhanced uptake of carnitine by perfused rat liver following starvation. Biochim Biophys Acta 896:96102

39. Rebouche CJ. Engel AG 1982 Carnitine transport in cultured muscle cells and skin fibroblasts from patients with primary systemic carnitine deficiency. In Vitro (Rockville) 18:495-500

40. Bahl JJ, Bressler R 1987 The pharmacology of carnitine. Annu Rev Pharmacol Toxicol 27:257-277

41. Bieber LL 1988 Carnitine. Annu Rev Biochem 57:261-283

42. Dreifuss FE, Santilli N, Langer DH, Sweeney KP, Moline KA, Menander KB 1987 Valproic acid hepatic fatalities: a retrospective review. Neurology 37:379-385

43. Li J, Norwood DL, Mao L-F, Schulz H 1991 Mitochondrial metabolism of valproic acid. Biochemistry 30:388-394

44. Stanley CA. Berry GT, Treem WR 1990 Differences in the evolution of carnitine deficiency among secondary carnitine deficiency disorders. Proceedings V International Congress Inborn Errors of Metabolism. Asilomar CA, June 1-5, W 17:10(abstr)

45. Nishida N, Sugimoto T, Araki A, Woo M, Sakane Y, Kobayashi Y 1987 Carnitine metabolism in valproate-treated rats: the effect of I-carnitine supplementation. Pediatr Res 22:500-503

46. Kesterson JW, Granneman GR, Machinist JM 1984 The hepatotoxicity of valproic acid and its metabolites in rats. I. Toxicologic, biochemical and histopathologic studies. Hepatology 4:1143-1152

47. Ito M. Ikeda Y, Arnez JG. Finocchiaro G. Tanaka K 1990 The enzymatic basis for the metabolism and inhibitory effects of valproic acid: dehydrogenation of valproyl-CoA by 2-methyl-branched-chain acyl-CoA dehydrogenase. Biochim Biophys Acta 1034:213-218

48. Haas R, Stumpf DA, Parks JK. Eguren L 1981 Inhibitory effects of sodium valproate on oxidative phosphorylation. Neurology 31:1473-1476

49. Sugimoto T, Araki A, Nishida N, Sakane Y, Woo M, Takeuchi T, Kobayashi Y 1987 Hepatotoxicity in rat following administration of valproic acid: effect of L-carnitine supplementation. Epilepsia 28:373-377

50. Thurston JH, Carroll JE, Hauhart RE, Schiro JA 1985 A single therapeutic dose of valproate affects liver carbohydrate, fat, adenylate amino acid. coenzyme $A$, and carnitine metabolism in infant mice: possible clinical significance. Life Sci 36:1643-1651

51. Coudé FX, Grimber G, Pelet A, Benoit Y 1983 Action of the antiepileptic drug, valproic acid, on fatty acid oxidation in isolated rat hepatocytes. Biochem Biophys Res Commun 115:730-736

52. Becker CM, Harris RA 1983 Influence of valproic acid on hepatic carbohydrate and lipid metabolism. Arch Biochem Biophys 223:381-392

53. Turnbull DM, Bone AJ, Bartlett K, Koundakjian PP. Sherratt HS 1983 The effects of valproate on intermediary metabolism in isolated rat hepatocyte and intact rats. Biochem Pharmacol 32:1887-1892 
54. Schulz H, Fong JC 1981 4-Pentenoic acid. Methods Enzymol 72:604-610

55. Benavides J, Martin A, Ugarte M, Valivieso F 1982 Inhibition by valproic acid of pyruvate uptake by brain mitochondria. Biochem Pharmacol 31:16331636

56. Haas R, Stumpf DA, Bergen BJ, Parks JK, Eguren L 1980 Inhibition of oxidative phosphorylation by sodium valproate. Neurology 30:420(abstr)

57. Rumbach L, Warter JM, Rendon A, Marescaux C, Micheletti G, Wakeman A 1983 Inhibition of oxidative phosphorylation in hepatic and cerebral mitochondria of sodium valproate-treated rats. J Neurol Sci 61:417-423

58. Hayasaka K, Takahashi I, Kobayashi Y, linuma K, Narisawa K, Tada K 1986 Effects of valproate on biogenesis and function of liver mitochondria. Neurology $36: 351-356$
59. Rogiers V, Vandenberghe Y, Vercruysse A 1985 Inhibition of gluconeogenesis by sodium valproate and its metabolites in isolated rat hepatocytes. Xenobiotica 15:759-765

60. Kay JD, Hilton-Jones D, Hyman N 1986 Valproate toxicity and ornithine carbamoyltransferase deficiency. (letter) Lancet 2:1283-1284

61. Appleton RE, Farrell K, Applegarth DA, Dimmick JE, Wong LT, Davidson AG 1990 The high incidence of valproate hepatotoxicity in infants may relate to familial metabolic defects. Can J Neurol Sci 17:145-148

62. Ater SB, Swinyard EA, Tolman KG, Madsen JA, Matsuo F 1984 Effects of SKF525A, phenobarbital, fasting, and carnitine on the anticonvulsant activity and neurotoxicity of valproate in mice. Epilepsia 25:599-604 